\title{
TRTaKadeMi
}

\section{Doğukan GEZER}

İçerik Pazarlanabildiği Kadar 'Kral’dır

\section{Röportaj: Recep ORHAN - Ümit ÇALIŞKAN}

\section{RÖPORTAJ}


Son yıllarda dijital medyadaki haberciliğiyle kendini gösteren GZT'nin Genel Yayın Yönetmeni Doğukan Gezer ile dijitalleşmenin ve sosyal medya mecralarının yayıncılığa etkisini konuştuk.

TRT Akademi Dergisi: Dijitalleşmenin sağladığı imkânlar ile "patronsuz gazetecilik" gibi bir kavramın ortaya çıktı̆ını görüyoruz. Bunun avantajları nedir? Geleceğini nasıl görüyorsunuz?

Doğukan Gezer: Teknolojinin imkânları ile gelişen yeni medya yayıncılığı, gazetecilik tarihi boyunca görülmemiş bir yeni sayfa açt. Daha önceleri bu mesleği icra etmek için iletişim aracının yapısına göre stüdyolar, matbaalar, yayın ya da dağıtım ağları gibi fiziki yapıların varlığı şarttı; daha ötesi buna ek olarak resmî olarak izinler alınması ve haber merkezi kadrolarının bu resmîyet çerçevesinde olması da gerekirdi.

Internetin her zaman övündüğümüz hız, erişim, kolaylık gibi özellikleri tüm bu ekosistemi bir internet bağlantısı ve telefon, bilgisayar gibi ekipmanların varlığına kadar indirgedi. Hâl böyle olunca son yıllarda karşı karşıya kaldığımız "patronsuz gazetecilik" kavramı önceleri öngörülemeyen bir şekilde hızla hayatımıza girdi. Yeni medya alanında her yeniliği avantajları ve dezavantajlarıyla birlikte okumanın gerekliliğine işaret etmek istiyorum.

Avantajlarda en öne çıkan unsur; gazetecilik yapma eyleminin daha kolay ve erişilebilir olmuş olması. Bir gazeteci, kendi yayın ilkeleri ile dilediği bir sosyal medyada ismini markalayarak yayıncılık yapabilmekte. Buradan yola çıkarak; geçmiş tecrübelerdeki patron-gazetecilik ilişkisinin de aynı potada eridiğini görüyoruz. Hâl böyle olunca karar alma mercisinde bir gazetecinin oturuyor olması; haber merkezi kadrolarınca da daha umutla karşılanan bir durum oldu.

Ancak işin geleceğine baktı̆̆ımızda; bu aynı potada eriyen iki kavram, işler büyüyünce yeniden bölünmeye gidebilme riski taşıyor. İki ayrı iş tanımının, büyük bir işletmede tek kişi altında toplanması, başlardaki avantajı dezavantaja çevirebilir. Bu nedenle ilerleyen yıllarda keskin olmasa da eskiye dönüş sinyallerini görebiliriz.

TRT Akademi Dergisi: Dijital mecralar, bireylerin daha özgür olduğu bir alan. Dijitale bir denetim gelmeli mi? Editoryal süreçleri siz nasıl yürütüyorsunuz?

Doğukan Gezer: Herkesin demokratik bir şekilde, dilediğince içerik üretmesi sloganı sosyal medyaların kuruluş aşamasında ne kadar görkemli karşılanmışsa da içerisinde olduğumuz dönemde bu özgürlüğün hemen herkesi tedirgin ettiğini de görüyoruz. 
Gazetecilik mesleğinden gidersek; kuruluşundan beri ilkeleri, öncelikleri ve çerçeveleri olmuş olan bu meslek, etki gücü itibariyle her zaman mesleği icra edenler tarafindan dikkatle yapılmıştır. Ancak şu an herkesin içerik ürettiğini; birçoğunun ise içerik üretirken değerlere eğilmediğini görüyoruz.

Burada sosyal medya mecralarının kuruluşlar motivasyonları nedeni ile denetimsiz dünya kurmuş olması, bu alana bir denetim gerekliliğini son yıllarda tartışmaya açmış durumda. Doğrulama platformları, resmî makamların bilgilendirmeleri ve güvenilir medya kuruluşlarının etkisini artırması, bu alanda olumlu bir rüzgâr estirse de içerik üreticinin doğrudan duyarlılıkla hareket ediyor olması şart.

GZT haber merkezi örneğinden gidersek editoryal süreçlerimizi her ne kadar yeni medya yayıncısı olsak da geleneksel gazetecilik refleksleriyle yürütüyoruz. Teyitlenmemiş haber yayınlamama, yalan haberle karşılaştı̆̆ımızda sorumluluk alıp bunu doğrulama gibi adımlar atma gayretindeyiz. Her editör, yaptığı işin etkilerinin ve olası erişimlerinin farkında. Bu nedenle yayın süreçlerinden çok önce, ilk aşamadan itibaren bir sorumluluk ile hareket etmek zorundayız.

TRT Akademi Dergisi: Tematik yayıncılık, dijital mecralarda yükselen bir grafiğe sahip. Habercilik anlamında (örneğin spor yayıncılığı, enerji yayıncılığı, sağlık vb.) tematik bir dijital kanala sahip olmak, geleceğin yayıncılık dünyası için nasıl bir imkân sunuyor?

Doğukan Gezer: En başta bahsettiğimiz gazetecilik için devasa yapılara ve sayfalar dolusu belgelere gerek olmadığı gerçeği, burada da karşımıza çıkıyor. Tematik yayıncılık hiç görmediğimiz kadar yükselen bir trendde. Bunun ilk nedeni herkesin yayıncılık yapabilmesi ancak ikinci neden daha önemli: Algoritmalar.

Algoritmalar, kendilerini üreten mühendislerce dahi tam olarak tanımlanamaz ancak verilen büyük bir ipucu var. Benzer içerik ile benzer hedef kitlenin buluşturuluyor olması. Örneğin YouTube gibi bir dijital mecrada yayıncı iseniz platform sizden benzer konularda ve tercihen tek bir temada yayın yapmanızı bekliyor. Bunun temel motivasyonu, size abone olan kişilere, ilgileri dışında bir şey göstermek istemiyor oluşları. Yemek videoları yapıyor iseniz size bu video türünü sevenler algoritma tarafindan yönlendiriliyor; bu gelen kişilere bir anda egzersiz videosu göstermek istenmeyen sonuçlar doğuracaktır. Bu mekanizma tüm sosyal medya markalarının ortak noktası olunca yayıncılar da bir anda tematik alanlara yönelme eğiliminde buldu kendilerini. Bu yolda devam ettikçe etkileşim oranları ciddi oranda artt ve daha da tematikleşme geldi. Artık yemek videosu yapmak da bir kısıt değil, hangi yemek türünü yaptığınız sizi gruplamaya başladı. 
TRT Akademi Dergisi: Dijitalleşme ve sosyal medya mecraları ile yayıncılık nasıl bir değişim yaşadı, yaşıyor? Dijitalleşmenin getirdiği yeni anlatım biçimleri ile ilgili ne söylersiniz?

Doğukan Gezer: Geleneksel medya ortamlarında bugün yayınlanan sayfalar ya da bültenlere baktığımızda; hemen öncesinde dijital medyada tükettiğimiz benzer içeriklerle bir kıyasa gidebilmek mümkün. Burada farklar bir bakışta dahi ortaya çıkabiliyor. En önemli değişim, şüphesiz içeriğin üretildiği ile sunulduğu zaman arasındaki farkta anlaşılıyor. Geleneksel medyada belli süreler beklenmesi gerekirken dijitalde herhangi bir hız bariyeri yok. İkinci değişim ise anlatım dili. Dijitalde "olduğu gibi" anlatma en değerli hikâye anlatım metotlarından biri. Bir içeriği arkadaşınıza anlatıyor gibi kolay, didaktik olmayan ve anlaşılır ifade etmek kıymetli. Dijitalde gelen bu yeni anlatım biçimi iletişim tarihi kadar eski olan hikâye anlatıcılığı rolünün de ne derece önemli olduğunu ortaya koydu. Duygusuz, sabit ve hatasız bir anlatıma karşın daha duygu yüklü bir hitap o dönemlerde olduğu gibi şimdi de karşılık buluyor.

Sunumlardan öte sunuş biçimleri de değişimin bir numaralı tanı̆̆ı. Bir video anlatısının dik formda, 15 saniyede yapılıyor olması; yıllar önce TV ve video içerik üreticileri için öngörülemeyecek bir yapıydı. Bunlara ek 360 derece kamera ile bir bölgeden yayın yapmak ya da metaverse evreninde sanal olarak bir araya gelmek... Bu gibi örnekler bu röportajı yaptı̆ımız sırada sayısını arttırıyor olmalı. Çünkü her geçen yayın dönemi, bir öncesine göre yeni sayfalar açtırıyor bizlere haber merkezlerinde.

TRT Akademi Dergisi: Son dönemde kişisel yayıncılığın ve kişisel markaların bazı kurumsal markaların dahi önüne geçtiğini görüyoruz. Bu değişimin sebebi nedir?

Doğukan Gezer: Herkesin yayıncılık yapabiliyor oluşu, bir süre sonra 'neden medya markasında çalışmalıyım?' sorusunun yanıtını ortadan kaldırdı ve bu yanıtsız soru, kişisel markaları öne çıkardı. İçerisinde bulunduğumuz dönemde kritik bir virajda olduğumuzu düşünüyorum; çünkü ilk kez iki farklı alan bu kadar dengelendi. Kişisel hesaplar, medya markaları ile denk bir hâle geldi. Bunu etkileşim oranlarına bakarak dahi kolaylıkla ölçmek mümkün.

Ayrıca algoritmanın işaret ettiğimiz sürprize kapalı yayıncılık istiyor oluşu da bu alanı besleyen bir diğer motivasyon. Bir kanala o kişi için abone oluyorsa kullanıcı, algoritma o kişinin içerik üretmesini bekler. Ancak medya markaları ise onlarca farklı ekran yüzü ile yayıncılık yapar ve bu bir yandan algoritmanın istediği bir durum değildir. Sosyal medyada algoritmanın sevdiği kazandığı için bu dönem 
kişisel hesapların etkileşimleri oldukça güçlü. Ancak bunun bir süre sonra kırılacağını; yüzlerce tekil hesap takip etmenin kullanıcıları yoracağını düşünüyorum. Bu yorgunluk sonucu güvenilir medya kuruluşları dijitalde aranıyor olacak ve peşine bu dijital markalara abone olma rüzgârı gelecektir.

TRT Akademi Dergisi: Geçtiğimiz günlerde Rusya'ya vlog çekmeye giden 2 muhabiriniz orada gözaltına alındı. Dijital muhabirler için hukuki süreç nasıl işliyor?

Doğukan Gezer: Arkadaşlarımız Rusya'ya turistik amaçla giderek Türk Dünyası alanında VLOG çekiyorlardı, bu nedenle mesleki olarak bir başlık altında değerlendiremeyiz maalesef. Ancak gözaltı sonrası sosyal medya destek kampanyamıza gelen milyonlarca katkıdan da gördük ki dijitalde muhabir olmanın geleneksele göre geri kalır bir yanı yok.

TRT Akademi Dergisi: Dijitalleşmenin getirdiği yeni gazetecilik modelinde; reklam, sponsorluk vb. ülkemizde yeni yeni oluşmaya başlayan ücretli üyelik, fonlama, tıklanma gelirleri gibi gelir modelleri oluşmaya başladığını görüyoruz. Bu yönüyle de geleneksel gazetecilikten/yayıncılıktan farklı bir durum söz konusu. Bu gelir modellerinin haberciliğe etkisi nedir?

Doğukan Gezer: Bundan 20 yıl önce dijital müzik dinlemeye, internetten film/dizi izlemeye para vereceğimizi söyleyen birini duysak dikkate almazdık ancak içerisinde bulunduğumuz dönemde aylık ortalama 100 TL dijital içerik tüketimlerine gidiyor. Buna platform aboneliği de dâhil bağış modeli yayın yapan yayıncılara verilen katkı da.

Yayıncılık dijitale taşındı ancak reklam gelirleri aynı oranda bu taşınmada yer almadı. İki temel sorun burada baş gösteriyor. Geleneksel markalar hâlen daha dijitalin gücünün farkına varmamış durumda; bu nedenle harcamalarının mümkün olduğunca geleneksel medyada eritiyor. Bu nispeten düzelebilir bir problem. İkincisi ise daha karanlık tarafta ve çözümü nispeten daha zor. İlk aşamayı aşıp gelen reklam bütçeleri Google gibi küresel markalarla ile karşılaşıyor. Amaç en ucuz yolla en çok müşteriye ulaşmak olunca başvuru kaynağı bu markalar oluyor. Bu da dijital yayıncıya pastada neredeyse dilim kalmamasına yol açıyor.

Fonlama, katkı gibi modeller Avrupa'da yayıncılık alanında karşılık alan; ülkemizde de yeni yeni denemelerine başlanan bir yeni yol. Sürdürülebilir gazetecilik için bu gibi modellerin artması ve daha önemlisi hacmini büyütmesi oldukça önemli. Haberciliğe en önemli etkisi, reklam veren gibi bir sorunsal denklemden tamamen çıkıyor ve içerik özgürce üretiliyor. Buna ek, gazeteci için de doğrudan motivasyon kaynağı oluyor. 
TRT Akademi Dergisi: Dijital medyayı ölçümlemek ne derece mümkün? Ölçümlenen verinin etkili bir şekilde kullanılması için nelerin yapılması gerekiyor?

Doğukan Gezer: GZT'nin haber merkezinde duvarda bir söz asılıdır: “izlemediğin şeyi ölçemez, ölçemediğin şeyi de yönetemezsin." Genel Müdürümüz Ömer Karaca'nın yaklaşık 5 yıl önce not düştüğü bu söz, aslında sorunuzun hem yanıtını hem de bu yanıtın ne kadar önemli olduğunu gösteriyor. Dijital medyanın ne kadar dezavantajından daha çok bahsetsek de en büyük avantajı yayıncılara sunduğu ölçüm metrikleri.

Geleneksel yayıncılıkla bir kıyas yine konunun daha net anlaşılmasını sağlayacaktır. Bir habere imza attı̆ınızı ve gazete manşetinde ya da ana haber bülteninde yayınlandığını düşünün. O haberin kaç kişi tarafindan görüldüğü, görenlerin kaçının okuduğu, okuyanların kaçının etkileşime girdiği gibi birçok soru anlamsız olacaktır. Çünkü herhangi bir şekilde ölçüm yapmak mümkün değildir. Dijitalde ise aynı haber örneğinden gidersek kaç kişinin, ne zaman ve hangi ilde okuduğu, okuyanların kaçının yazıyı arkadaşlarına gönderdiği, arkadaşların kaçının etkileşime girdiği gibi her detay rapor olarak birkaç tuşla karşınıza gelecektir.

Tabi bu verinin veriliyor olması yeterli bir düzey değildir. Elde edilen bu sonuçların okunması ve stratejilerin bu yönde inşa edilmesi oldukça önemli. GZT'de her yayın için benzer bir mekanizma işletiyoruz. Öncesinde trendlerin araştrılmasıyla başlayan süreç; yayın gününün ve platformunun seçimine, sonrasında ise etkilerine kadar çok yönlü bir ölçüm süzgecinden geçiyor. Bu ölçümler ciddi oranda bizim bir sonraki yayınımızı etkiliyor ve gelişimine katkı sağlıyor.

TRT Akademi Dergisi: Sosyal medyada yankı fanusu, bireyin ötekinden habersiz kalacağı bir dünya oluşturuyor. Bunu habercilik açısından değerlendirebilir misiniz?

Doğukan Gezer: Yankı odası kavramı içerisindekilerin hiçbir zaman o odada olduğunu fark edemediği dünyalar inşa ediyor. Sosyal medya mecraları, yoğun etkileşimler için yankı odasına yapıları gereği ön açıyor. Kullanıcılara yansıyan bu probleme karşı medya markaları yıkıcı bir şekilde hareket etmeli ve yankı odasının karşısında durmalı. Özellikle nitelikli medya okuryazarlığının kazandırılması ve toplumsal iş birliği için bu medyanın üzerinde bulunan bir sorumluluk. Bu nedenle yeni medya markaları hem yankı odası oluşturacak söylemlerden uzak durmalı hem de yankı odasının doğduğu anlarda uyarılarda bulunarak kitleyi bilinçlendirmeli. 
Yankı odasına girildiği an linç edilme riski, gazetecinin önünde duruyor. Bu hassas alanda ne olursa olsun doğru haberi vermek önemli. Ayrıca burada gazetecinin da bu psikolojinin farkında olarak bir dil benimsemesi, sonuca daha kolay ulaşt-racaktır.

TRT Akademi Dergisi: Sosyal medya Arap Baharında kitleler için özgürlüğü ifade ederken bugün aynı kitleleri cam bir fanusa hapsediyor. Yarın ne olacak? Kitlesel hareketlerde sosyal medyanın etkisine inanıyor musunuz?

Doğukan Gezer: Sosyal medya geçmiş tecrübelere oranla bugün daha etkili bir alanda. Ancak gözden kaçmaması gereken bir fark var. Daha önceleri hiçbir şekilde süreçlere müdahil olmayan bu mecralar, Trump'ın Twitter hesabının kapatıldığı örnekte olduğu gibi artık daha aktifler. Hâl böyle olunca olası bir benzer krizde nasıl rol alacaklarını öngörmek daha mümkün. Artk sosyal mecraların da bir taraf olduğunu ve aktif bir şekilde bu tarafgirliklerini gösterdiklerini görüyoruz.

Buna kullanıcıların en üst perdeden karşı çıkması ve olası krizler için şimdiden güvenli alanlar inşa etmeleri gerekiyor. Buna medya kuruluşlarından sosyal medya mecralarına kadar birçok enstrüman eklenebilir.

TRT Akademi Dergisi: Kaliteli içerik mi yoksa etkileşimi yüksek içerik mi? Bu alanda bir şeyler üretmek isteyen gençlere tavsiyeleriniz ne olur?

Doğukan Gezer: Yayıncılık tarihinde maalesef pek tartışılmayan bir soru ile karşı karşıyayız. Bir içerik kaliteli ve iyi ise daha çok kişiye erişir, etkisi kısa sürede büyürdü. Ancak yeni medya dünyasında bu soru, sorun olarak karşımıza gelmeye başladı. Burada genç iletişimcilerin ve adayların, öğrenimleri sürecinde sık duydukları bir tabir "İçerik kraldır." sözüne bakmak, sorunun tespitinde yardımcı olacaktır. Bu sözün miadını kısmen doldurduğunu ve artık içeriğin pazarlanabildiği kadar "kral" olduğunu düşünüyorum. Ne kadar kaliteli bir iş yapıyorsak yapalım; bunu pazarlayamıyorsak etkisinin beklentinin çok gerisinde olacağına şaşırmamak gerekiyor.

Peki, pazarlamak için ne yapmalıyız? Birincisi, yeni medya dünyasının sunduğu tüm imkânlardan yararlanmak gerek. Ayrıca, "İçeriğime güveniyorum." yerine, "Güvendiğim içeriği nasıl daha çok kişiye ulaştırırım?" sorusuyla yola çıkılmalı. Algoritma mekanizması ise adeta bir mayınlı arazi. Burada hareket etmek ve sonuç almak öngörülemeyecek kadar güç ancak yine de her sosyal medya mecrasının algoritmasını analiz ederek yayına çıkmak daha iyi sonuçları beraberinde getirecektir. 


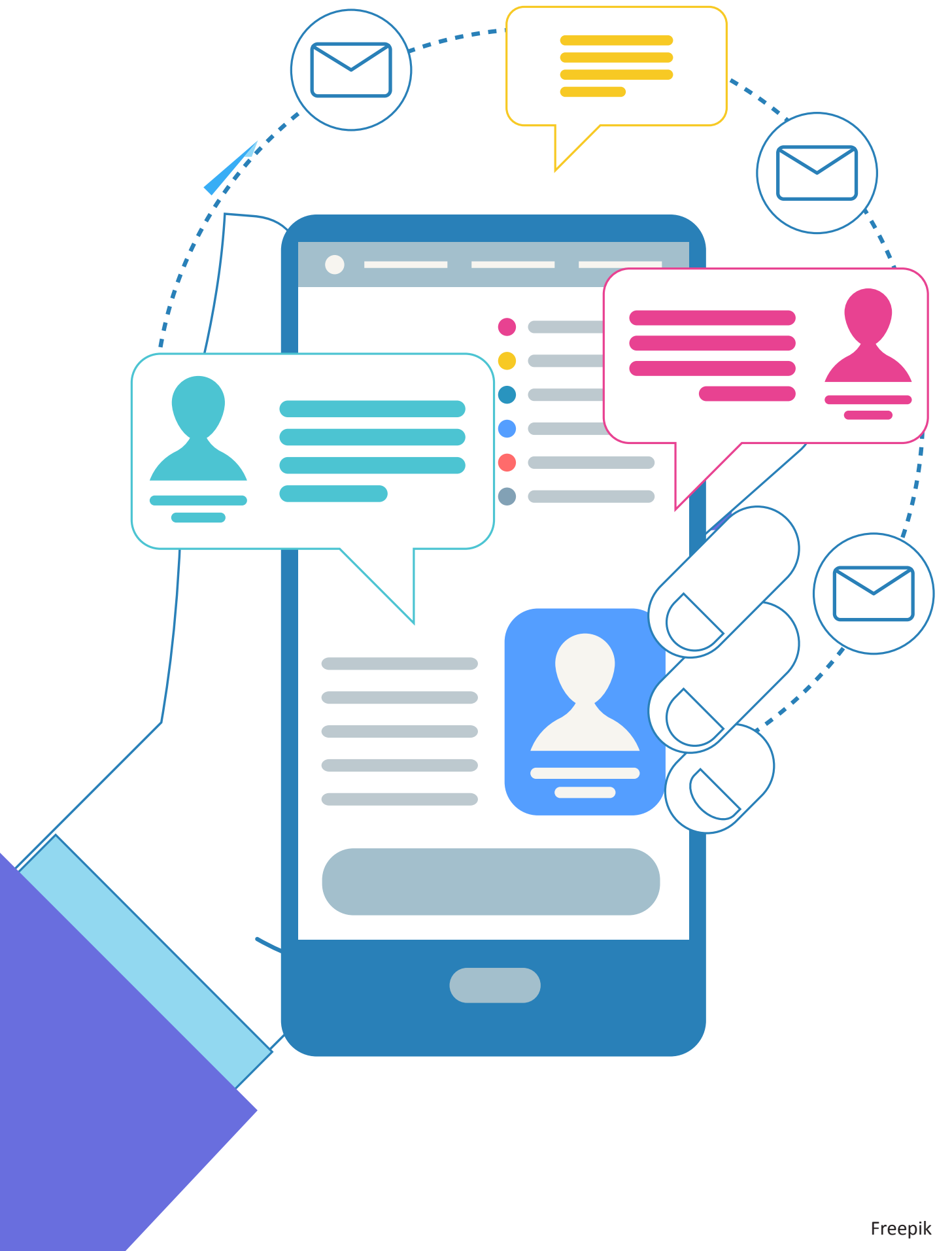

